\title{
Glucokinase activating mutation causing hypoglycaemia diagnosed late in adult who fasts for Ramadhan
}

\author{
Wann Jia Loh@1, Lily Mae Dacay', Clara Si Hua Tan², Su Fen Ang2, Fabian Yap³, \\ Su Chi Lim 10 2,4,5 and Joan Khoo'
}

1Department of Endocrinology, Changi General Hospital, Singapore, Singapore, ${ }^{2}$ Clinical Research Unit, Khoo Teck Puat Hospital, Singapore, Singapore, ${ }^{3}$ Department of Paediatric Endocrinology, KK Women's and Children's Hospital, Singapore, Singapore, ${ }^{4}$ Diabetes Centre, Admiralty Medical Centre, Singapore, Singapore, and ${ }^{5}$ Saw Swee Hock School of Public Health, National University Hospital, Singapore, Singapore
Correspondence should be addressed to WJ Loh

Email

loh.wann.jia@singhealth. com.sg

\section{Summary}

Activating mutation of glucokinase gene (GCK) causes resetting of insulin inhibition at a lower glucose threshold causing hyperinsulinaemic hypoglycaemia (GCK-HH). This is the first reported case who tolerated years of regular fasting during Ramadhan, presenting only with seizure and syncope now. We describe a case with GCK gene variant p.T65I diagnosed in a 51-year-old woman with hypoglycaemia unawareness even at glucose level of $1.6 \mathrm{mmol} / \mathrm{L}$. Insulin and C-peptide levels during hypoglycaemia were suggestive of hyperinsulinism, but at a day after intravenous glucagon, hypoglycaemia occurred with low insulin and C-peptide levels, pointing against insulinoma as the underlying aetiology. Imaging studies of the pancreas and calcium arterial stimulation venous sampling were unremarkable. A review of old medical records revealed asymptomatic hypoglycaemia years ago. Genetic testing confirmed activating mutation of GCK. Hypoglycaemia was successfully controlled with a somatostatin analogue. This case highlights the importance of consideration of genetic causes of hypoglycaemia in adulthood, especially when imaging is uninformative.

\section{Learning points:}

- Consider genetic causes of endogenous hyperinsulinism hypoglycaemia in adulthood, especially when imaging is uninformative.

- Late presentation of activating mutation of GCK can occur because of hypoglycaemia unawareness.

- Long-acting somatostatin analogue may be useful for the treatment of activating mutation of GCK causing hypoglycaemia.

- Depending on the glucose level when the blood was taken, and the threshold of glucose-stimulated insulin release (GSIR), the serum insulin and C-peptide levels may be raised (hyperinsulinaemic) or low (hypoinsulinaemic) in patients with activating mutation of GCK.

- Glucagon may be useful to hasten the process of unmasking the low insulin level during hypoglycaemia below the GSIR level of which insulin released is suppressed.

\section{Background}

We present here a unique case of activating mutation of glucokinase gene $(G C K)$ causing hyperinsulinism hypoglycaemia (GCK-HH). This is the first reported case who tolerated decades of regular fasting during Ramadhan, presenting only with seizure and syncope now. Her hypoglycaemia unawareness is severe as she 
remains asymptomatic even with glucose of $1.6 \mathrm{mmol} / \mathrm{L}$, which can partially explain her late diagnosis of GCK-HH. Hypoglycaemia unawareness due to downregulation of counter-regulatory hormone response contributed to her delayed presentation and absence of Whipple's triad. She had left-sided camptodactyly with right hemisphere atrophy, possibly secondary to hypoglycaemia during brain development. The use of intravenous glucagon during the $72 \mathrm{~h}$ fast appeared to hasten the process of unmasking the low insulin level during hypoglycaemia below the glucosestimulated insulin release (GSIR) level of which insulin released is suppressed.

\section{Case presentation}

A 51-year-old female of Muslim religion was admitted to our hospital after she sustained a right femur fracture following a syncope. On the second day of admission, she had an episode of generalised tonic-clonic seizure. She was found to have multiple asymptomatic hypoglycaemia readings $2.3-3 \mathrm{mmol} / \mathrm{L}$ occurring typically in the morning and postprandially (3-3.5 mmol/L). Urine toxicology screens for sulphonylurea and meglitinides were negative.

She had abnormal developmental history. She had camptodactyly of her left hand since she was an infant. Although she had below average IQ, she was communityambulant, had a friendly personality and independent in her daily activities. She was born at full term in a village and did not visit the doctors regularly. There was no other significant medical history. including seizure or syncope, during her childhood. She complained of a few episodes of dizziness in the recent year, which were precipitated by

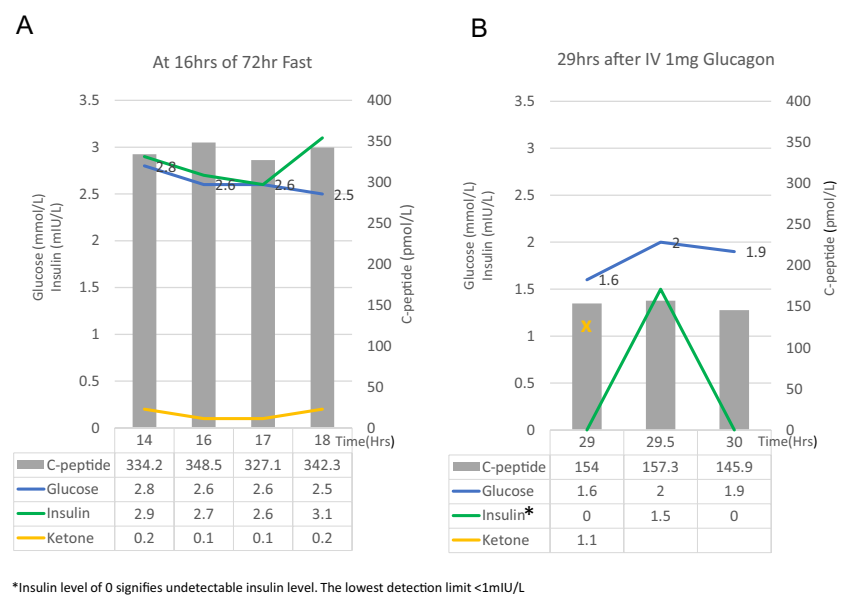

\section{Figure 1}

Venous glucose, serum insulin and C-peptide levels at 16 th $\mathrm{h}$ of $72 \mathrm{~h}$ fast (A) and at $29 \mathrm{~h}$ after IV glucagon was given illustrated in (B). fasting, and hence she avoided fasting. Prior to that, she, along with her family, religiously fasted for $14 \mathrm{~h}$ during Ramadhan month every year since she was a teenager. She weighed $64 \mathrm{~kg}$, her height was $1.53 \mathrm{~m}$ and her BMI was $27 \mathrm{~kg} / \mathrm{m}^{2}$.

\section{Investigation}

Her blood tests were normal for full blood count, renal panel, liver panel, thyroid function, lipid panel and serum ammonia. A $250 \mu \mathrm{g}$ synacthen test was normal with a peak cortisol level of $577 \mathrm{nmol} / \mathrm{L}$. She did not have growth hormone deficiency as evident by her normal glucagon stimulation test, achieving a peak of 59.2 MU/L.

A review of her old medical records revealed that she was seen in outpatient clinic 11 years ago for an incidental finding of asymptomatic low venous glucose of $1.9 \mathrm{mmol} / \mathrm{L}$ during a general health check. An inpatient fast revealed a nadir glucose of $2.4 \mathrm{mmol} / \mathrm{L}$ at $44 \mathrm{~h}$ after initiation of fast, with hyperinsulinism hypoglycaemia (venous glucose 2.4 $\mathrm{mmol} / \mathrm{L}$, insulin $2.8 \mathrm{mIU} / \mathrm{L}, \mathrm{C}$-peptide $430 \mathrm{pmol} / \mathrm{L}$ ) albeit a borderline insulin level. A CT scan of her abdomen was normal. She was lost to follow-up as she was asymptomatic. In view of the significant time-lapse from her 1st asymptomatic presentation years ago and the absence of Whipple's triad, an inpatient $72 \mathrm{~h}$ fast was repeated (Fig. 1).

At $16 \mathrm{~h}$ of the fast, venous glucose of $2.5 \mathrm{mmol} / \mathrm{L}$ was reached with C-peptide $348.5 \mathrm{pmol} / \mathrm{L}$ and insulin 2.7 $\mathrm{mIU} / \mathrm{L}$, suggestive of hyperinsulinism hypoglycaemia, albeit another borderline insulin level. Her venous glucose increased by $>1.4 \mathrm{mmol} / \mathrm{L}$ from 2.5 to $5.5 \mathrm{mmol} / \mathrm{L}$, indicating she had hepatic glycogen stores from insulin excess at this point (1). In view of the borderline fasting insulin level, fasting was continued with hourly glucose monitoring with the aim to reach venous glucose $<2.5$ $\mathrm{mmol} / \mathrm{L}$. Capillary glucose remained at $2.6-3.5 \mathrm{mmol} / \mathrm{L}$ until at $29 \mathrm{~h}$ later after the glucagon injection, her venous glucose dropped to $1.6 \mathrm{mmol} / \mathrm{L}$, with undetectable serum insulin levels and low C-peptide levels (insulin $<1 \mathrm{mIU}$, C-peptide $154 \mathrm{pmol} / \mathrm{L}$ ), Fig. 1. At this point, cortisol and growth hormones were taken which showed suboptimal responses, suggesting downregulation of counterregulatory hormones in hypoglycaemia unawareness (2). At 0,30 , and 60 min after the onset of hypoglycaemia 1.6 $\mathrm{mmol} / \mathrm{L}$ was detected, cortisol levels were 483, 416, 389 $\mathrm{mmol} / \mathrm{L}$, GH levels were $0.2,0.5$, and $3.5 \mathrm{MU} / \mathrm{L}$, and IGF-1 levels were 34.4, 32, and $30.9 \mu \mathrm{g} / \mathrm{L}$ (NR 100-314 $\mu \mathrm{g} / \mathrm{L}$ ), respectively. The suppressed serum ketones during the fast and only slightly increased to $1.1 \mathrm{mmol} / \mathrm{L}$ but still much lower than $2.7 \mathrm{mmol} / \mathrm{L}$ (1) reflect that ketoacid formation 
has initiated but not yet at starvation ketosis state. She remained asymptomatic throughout the whole fast. In view of her borderline insulin levels during hypoglycaemia despite raised C-peptide values, proinsulin level was measured and was raised at $48 \mathrm{pmmol}$ when glucose was $2.6 \mathrm{mmol} / \mathrm{L}$ (proinsulin NR $<5 \mathrm{pmol} / \mathrm{L}$ (1)).

The pancreatic imaging scan using CT and MRI were negative for insulinoma. Calcium arterial stimulation venous sampling of the pancreas did not localise hypersecretion of insulin to any pancreatic region (Fig. 2). Insulin antibodies were negative and IGF-2: IGF-1 ratio was $4.8(\mathrm{NR}<10)$. An activating GCK missense variant (NM_000162.5 (GCK): c.194C >T p.[Thr65Ile];[=]) known to be associated with GCK-HH (3) was identified by targeted next-generation sequencing using the Ion Torrent PGM $^{\mathrm{m}}$ (Life Technologies). All protein-coding regions and their flanking splice sites, the 5'UTR and 3'UTR regions, were sequenced for 16 maturity-onset diabetes of the young (MODY)-associated genes, including GCK. Variants identified were annotated employing Alamut ${ }^{\oplus}$ software, classified by American College of Clinical Genetics and Genomics (ACMG) guidelines (4), and those classified as pathogenic/likely pathogenic were verified by bi-directional Sanger sequencing. The rare variant p.Thr65Ile is found in exon 2 of the GCK gene (RefSeqGene NG_008847.2) and resides in the allosteric activator site, which is involved in transforming the enzyme from the active to non-active state. Her mother and brother were tested negative for the genetic mutation. We could not confirm if this was a de novo variant as her father could not be tested. He died from ruptured appendicitis in his 60s, and he was not known to have hypoglycaemia before.

CT and MRI brain showed that she had right cerebral hemisphere atrophy, which was likely a developmental abnormality (Fig. 3). This could explain her left hand and left foot camptodactyly. Silver-Russell syndrome was also considered in view of the camptodactyly and reduced IQ. However, she had normal head circumference and asymmetry of limbs could not be ascertained in view of femur fracture and camptodactyly. Genetic tests for SilverRussell syndrome were negative; methylation studies of 11 p15 and chromosomal microarray analysis were normal.

\section{Treatment}

Management of hypoglycaemia was challenging initially. She had hypoglycaemia despite intravenous dextrose and frequent meals. Her hypoglycaemia was not controlled with frequent meals. She had severe muscle stiffness, painful joints and leg oedema after three doses of diazoxide $100 \mathrm{mg}$ BD. While the oedema of her legs was tolerable, the generalised muscle stiffness and painful hand joints prohibited her movements. The adverse events resolved on stopping diazoxide. On rechallenging diazoxide 1 month

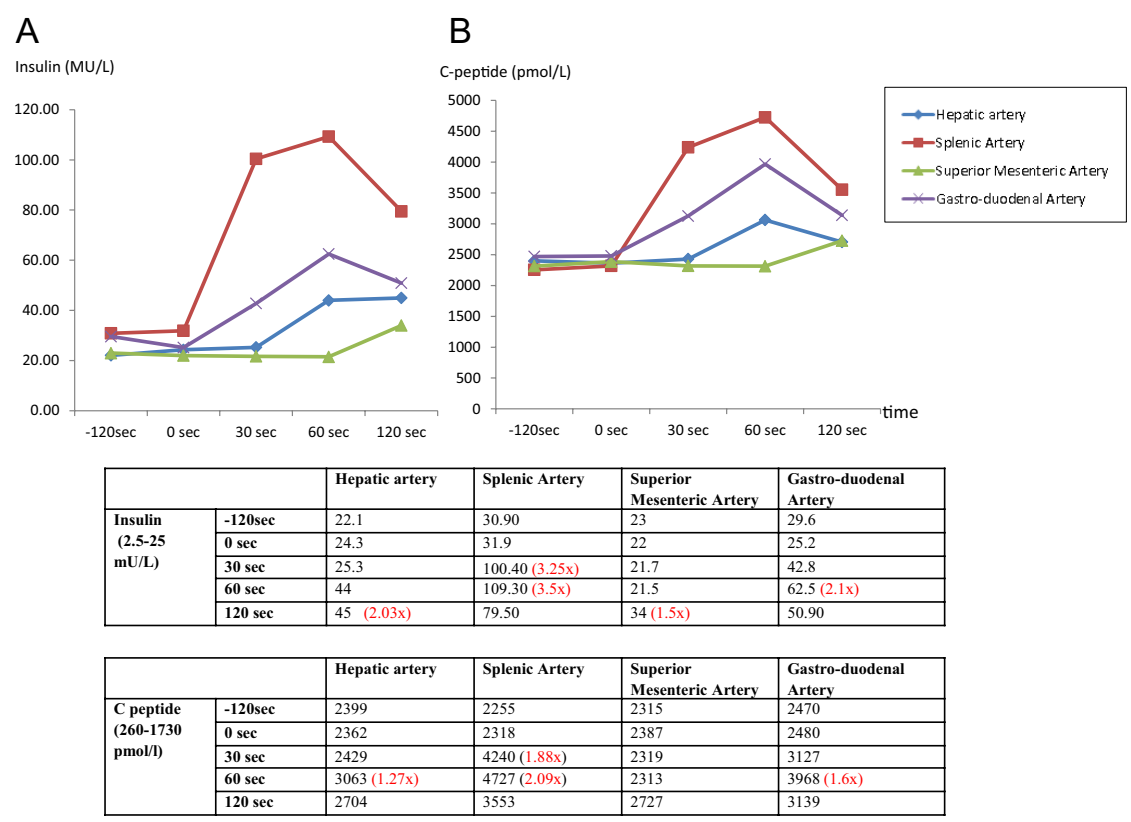

Figure 2

Calcium arterial stimulation venous sampling showed that the rise of insulin (A) and C-peptide (B) were not localised to any particular pancreatic region, although the highest rise was in the region supplied by the splenic artery. A significant rise was taken as >two times elevation from baseline, with the symbol $\times$ denoting the number of multiplication from baseline. 

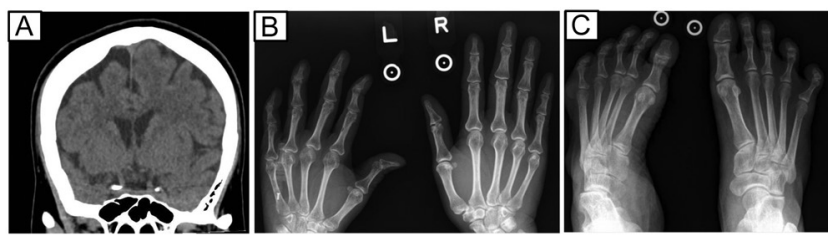

Figure 3

(A) CT brain showed right hemisphere atrophy. (B) Flexion deformity of the distal interphalangeal joints of the left $4^{\text {th }}$ and $5^{\text {th }}$ fingers due to camptodactyly. (C) Flexion deformity of both feet but left more than right.

later, the same adverse events occurred after two doses, and hence diazoxide was stopped. Anti-epileptic valproate was temporarily switched to phenytoin for hyperglycaemic effect (5), but this did not help. Monthly injections of somatostatin analogue Sandostatin LAR $20 \mathrm{mg}$ ameliorated hypoglycaemia $<3.5 \mathrm{mmol} / \mathrm{L}$ as seen using continuous glucose monitoring. This was switched to Lanreotide LAR $120 \mathrm{mg}$ for cost reasons with a good response. Her HbA1c improved from $<4.3 \%$ (i.e. lower than detection limit) to $4.9 \%$ on treatment.

\section{Outcome and follow-up}

Four years on, her hypoglycaemia remains well controlled on somatostatin analogue, with the lowest glucose of 3.2$3.3 \mathrm{mmol} / \mathrm{L}$ occasionally.

\section{Discussion}

Clinically and biochemically, it can be difficult to distinguish between insulinoma and $\mathrm{CHI}$ but critically important to do so because the management is quite different. The biochemical criteria from $72 \mathrm{~h}$ fast to diagnose insulinoma are defined by glucose $<3 \mathrm{mmol} / \mathrm{L}$, insulin $\geq 3 \mathrm{mIU} / \mathrm{L}$ (18 pmol/L), and C-peptide $>200 \mathrm{pmol} / \mathrm{L}$ (1). These criteria do not differentiate between insulinoma and GCK-HH, unless hypoglycaemia was below the glucose-stimulated insulin release (GSIR) threshold in GCK-HH. Thus, GCK-HH may have either positive or even negative asymptomatic $72 \mathrm{~h}$ fast (2). We found that continuing to monitor glucose and insulin levels after a glucagon injection was useful to detect hypoinsulinaemic hypoglycaemia in GCK-HH. The glucagon-induced glycogenolysis may have hasten the unmasking of her GSIR level at which endogenous hyperinsulinism is suppressed. Unlike GCK-HH, insulinoma would persistently have hyperinsulinism due to autonomous production regardless of venous glucose level or glycogen status. Glucokinase is a major controller that promotes liver glycogen synthesis (6). Perhaps, the metabolic adaptation of GCK-HH controlling glycogenesis and glycogenolysis at a lower GSIR, coupled with hypoglycaemia unawareness explains why this patient with GCK-HH could withstand fasting during Ramadhan for many years, while patients with insulinoma are unable to (7). Our observation suggests there is a risk of hypoglycaemia post-glucagon, especially in those with lower glycogen reserves.

Understanding GCK-HH may provide mechanistic insight to the use of glucokinase activators (GKA) as a treatment for type 2 diabetes. Non-selective GKA studies were disappointing in terms of rapid decline of hypoglycaemia efficacy and causing hepatic steatosis (6). Hepatoselective GKA TTP399 showed promising results of glucose-lowering effect and yet without causing hepatic steatosis (8). Unlike non-selective GKA, which increased glucagon and insulin levels, the liver-selective GKA TTP399 reduced plasma glucagon without change of insulin levels (8). Since monogenic diabetes due to inactivating GCK gene mutation (MODY2) have increased glycaemic threshold for glucagon secretion, activating-mutation of GCK may have decreased glucagon counterregulatory response during hypoglycaemia $(2,9)$. Lower glucagon response may thus be protective yet also contributing to hypoglycaemia unawareness. Further studies are needed to understand the role of glucagon in GCK-HH and GKA.

$\mathrm{CHI}$, otherwise called hyperinsulinism in infancy or nesidioblastosis, is most often diagnosed at infancy because of the early symptoms of poor feeding, floppiness, and jitteriness (10). Among the 11 different genes associated with CHI, GCK-HH is less common than ABCC8 and KCNJ11 (11). About 20 GCK-HH mutations have been reported with the majority being missense mutations in 95\% (11). GCK-HH presents with a wide spectrum of phenotypic features even within the same family with respect to presentation, age, severity, treatment response and hypoglycaemia awareness $(2,6,12,13)$. Although commonly presenting as neonates, late diagnosis has rarely been reported via cascade screening (6) with the oldest patient being 77 years old. Affected family members have been identified because of the autosomal dominant inheritance $(2,6)$. Unlike other causes of CHI, GCK-HH lowers the threshold for GSIR and usually responds poorly to the suppressive effect of insulin release by diazoxide (14). Whilst somatostatin analogue experience is limited and not effective for some patients (6), this patient presented herein had an excellent clinical response. 
The absence of family history does not exclude GCK-HH because mutations could be de novo and results in a variable spectrum of symptoms $(11,13)$. Patients presenting with de novo mutation tend to be unresponsive to diazoxide, have macrosomia and less adult onset (11).

$\mathrm{CHI}$ causes neonatal-infantile hypoglycaemia leading to permanent neurodevelopmental deficits such as motor and speech deficits, epilepsy, and mental retardation in $20-50 \%$ of survivors $(10,15)$. Specific regions of brain injury associated with neonatal hypoglycaemia on MRI are the white matter of posterior regions, cortex, basal ganglia and pulvinar injury, depending on the age of symptomatic hypoglycaemia $(16,17,18)$. Although mental retardation and speech deficits could be explained by hypoglycaemia, the asymmetrical hemisphere damage, in this case, was atypical. Generalised cerebral atrophy on MRI were found in $22.5 \%$ of patients with $\mathrm{CHI}$ but none with localised cerebral atrophy (19). We postulate that in this case, the neurological deficit causing hemisphere agenesis, camptodactyly, mental retardation and epilepsy were caused by hypoglycaemia during the critical brain developmental phase of neonatal-infantile period. Neonatal hypoglycaemia itself is an important cause of hypoxic-ischaemic encephalopathy (16). Whilst expectedly, the MRI changes of hypoglycaemia-induced injuries are usually symmetrical $(16,17)$, asymmetrical brain damages have been described in a case report (18). A 5 years old male with hypoglycaemia due to glycogen storage disease had right temporal lobe seizure causing status epilepticus and MRI brain showed atrophy of right hemisphere 1 month later (18). Asymmetrical changes of basal ganglia causing hemichorea-hemiballismus secondary to hyperglycaemia have been commonly described (20), also highlighting that biochemical glucose derangements can lead to asymmetrical brain damages.

In conclusion, GCK-HH should be considered as a differential diagnosis in an adult with hypoglycaemia, especially when imaging is uninformative. Genetic testing in such cases is invaluable as our case demonstrated that pancreatectomy could be avoided with the use of somatostatin analogue. The use of glucagon test during $72 \mathrm{hr}$ fast may be useful. Repeating insulin, C-peptide and proinsulin levels, if normal, are worthwhile in patients with suspected GCK-HH.

\section{Patient's perspective}

The patient and family were satisfied with the treatment and outcome because there were less need for multiple feeding throughout the day and night, less worry of hypoglycaemia during sleep and hypoglycaemiarelated complications.

\section{Declaration of interest}

The authors declare that there is no conflict of interest that could be perceived as prejudicing the impartiality of the research reported.

\section{Funding}

This research did not receive any specific grant from any funding agency in the public, commercial or not-for-profit sector.

\section{Patient consent}

Informed consent has been obtained from the patient and the patient's guardian for publication of the case report and accompanying images.

\section{Author contribution statement}

L W J wrote the draft, analyse the patient's data, revised the manuscript and is the primary physician of the patient. $\mathrm{D} \mathrm{L} \mathrm{M}$, and $\mathrm{K} \mathrm{H}$ contributed to the patient's care. T S H, A S H and L S C performed the genetic analysis of the patient. L W J, T S H, A S H, Y F, L S C and $\mathrm{KJ}$ are involved in the data interpretation. All authors were involved in the revision of the manuscript.

\section{References}

1 Cryer PE, Axelrod L, Grossman AB, Heller SR, Montori VM, Seaquist ER, Service FJ \& Endocrine Society. Evaluation and management of adult hypoglycemic disorders: an Endocrine Society Clinical Practice Guideline. Journal of Clinical Endocrinology and Metabolism 200994 709-728. (https://doi.org/10.1210/jc.2008-1410)

2 Christesen HB, Brusgaard K, Beck Nielsen H \& Brock Jacobsen B. Non-insulinoma persistent hyperinsulinaemic hypoglycaemia caused by an activating glucokinase mutation: hypoglycaemia unawareness and attacks. Clinical Endocrinology 200868 747-755. (https://doi. org/10.1111/j.1365-2265.2008.03184.x)

3 Osbak KK, Colclough K, Saint-Martin C, Beer NL, BellannéChantelot C, Ellard S \& Anna AL. Update on mutations in glucokinase (GCK), which cause maturity-onset diabetes of the young, permanent neonatal diabetes, and hyperinsulinemic hypoglycemia. Human Mutation 200930 1512-1526. (https://doi. org/10.1002/humu.21110)

4 Richards S, Aziz N, Bale S, Bick D, Das S, Gastier-Foster J, Grody WW, Hegde M, Lyon E, Spector E, et al. Standards and guidelines for the interpretation of sequence variants: a joint consensus recommendation of the American College of Medical Genetics and Genomics and the Association for Molecular Pathology. Genetics in Medicine 201517 405-424. (https://doi.org/10.1038/gim.2015.30)

5 Imanaka S, Matsuda S, Ito K, Matsuoka T \& Okada Y. Medical treatment for inoperable insulinoma: clinical usefulness of diphenylhydantoin and diltiazem. Japanese Journal of Clinical Oncology 198616 65-71. (https://doi.org/10.1093/oxfordjournals.jjco. a039117)

6 Challis BG, Harris J, Sleigh A, Isaac I, Orme SM, Seevaratnam N, Dhatariya K, Simpson HL \& Semple RK. Familial adult onset hyperinsulinism due to an activating glucokinase mutation: implications for pharmacological glucokinase activation. Clinical Endocrinology 201481 855-861. (https://doi.org/10.1111/cen.12517)

7 Fouda MA \& Malabu UH. Insulinoma in Saudi Arabia: a twenty-year hospital study. Medical Journal of Malaysia 200863 182-184.

8 Vella A, Freeman JLR, Dunn I, Keller K, Buse JB \& Valcarce C. Targeting hepatic glucokinase to treat diabetes with TTP399, a hepatoselective 
glucokinase activator. Science Translational Medicine 201911 eaau3441. (https://doi.org/10.1126/scitranslmed.aau3441)

9 Hussain K, Bryan J, Christesen HT, Brusgaard K \& Aguilar-Bryan L. Serum glucagon counterregulatory hormonal response to hypoglycemia is blunted in congenital hyperinsulinism. Diabetes 2005 54 2946-2951. (https://doi.org/10.2337/diabetes.54.10.2946)

10 Ludwig A, Enke S, Heindorf J, Empting S, Meissner T \& Mohnike K. Formal neurocognitive testing in 60 patients with congenital hyperinsulinism. Hormone Research in Paediatrics 201889 1-6. (https:// doi.org/10.1159/000481774)

11 Ping F, Wang Z \& Xiao X. Clinical and enzymatic phenotypes in congenital hyperinsulinemic hypoglycemia due to glucokinaseactivating mutations: a report of two cases and a brief overview of the literature. Journal of Diabetes Investigation 201910 1454-1462. (https:// doi.org/10.1111/jdi.13072)

12 Gutgold A, Gross DJ, Glaser B \& Szalat A. Diagnosis of ABCC8 congenital hyperinsulinism of infancy in a 20-year-old man evaluated for factitious hypoglycemia. Journal of Clinical Endocrinology and Metabolism 2017 102 345-349. (https://doi.org/10.1210/jc.2016-3254)

13 Cuesta-Munoz AL, Huopio H, Otonkoski T, Gomez-Zumaquero JM, Nanto-Salonen K, Rahier J, López-Enriquez S, García-Gimeno MA, Sanz P, Soriguer FC, et al. Severe persistent hyperinsulinemic hypoglycemia due to a de novo glucokinase mutation. Diabetes 2004 53 2164-2168. (https://doi.org/10.2337/diabetes.53.8.2164)

14 Sayed S, Langdon DR, Odili S, Chen P, Buettger C, Schiffman AB, Suchi M, Taub R, Grimsby J, Matschinsky FM, et al. Extremes of clinical and enzymatic phenotypes in children with hyperinsulinism caused by glucokinase activating mutations. Diabetes 200958 1419-1427. (https://doi.org/10.2337/db08-1792)
15 Aynsley-Green A, Hussain K, Hall J, Saudubray JM, Nihoul-Fekete C, De Lonlay-Debeney P, Brunelle F, Otonkoski T, Thornton P \& Lindley KJ. Practical management of hyperinsulinism in infancy. Archives of Disease in Childhood: Fetal and Neonatal Edition 200082 F98-F107. (https://doi.org/10.1136/fn.82.2.f98)

16 Wong DS, Poskitt KJ, Chau V, Miller SP, Roland E, Hill A \& Tam EW. Brain injury patterns in hypoglycemia in neonatal encephalopathy. American Journal of Neuroradiology 201334 1456-1461. (https://doi. org/10.3174/ajnr.A3423)

17 Yalnizoglu D, Haliloglu G, Turanli G, Cila A \& Topcu M. Neurologic outcome in patients with MRI pattern of damage typical for neonatal hypoglycemia. Brain and Development 200729 285-292. (https://doi. org/10.1016/j.braindev.2006.09.011).

18 Gataullina S, De Lonlay P, Dellatolas G, Valayannapoulos V, Napuri S, Damaj L, Touati G, Altuzarra C, Dulac O \& Boddaert N. Topography of brain damage in metabolic hypoglycaemia is determined by age at which hypoglycaemia occurred. Developmental Medicine and Child Neurology 201355 162-166. (https://doi.org/10.1111/dmcn.12045)

19 Helleskov A, Melikyan M, Globa E, Shcherderkina I, Poertner F, Larsen AM, Filipsen K, Brusgaard K, Christiansen CD, Hansen LK, et al. Both low blood glucose and insufficient treatment confer risk of neurodevelopmental impairment in congenital hyperinsulinism: a multinational cohort study. Frontiers in Endocrinology 20178156. (https://doi.org/10.3389/fendo.2017.00156)

$20 \mathrm{Oh} \mathrm{SH}$, Lee KY, Im JH \& Lee MS. Chorea associated with non-ketotic hyperglycemia and hyperintensity basal ganglia lesion on T1-weighted brain MRI study: a meta-analysis of 53 cases including four present cases. Journal of the Neurological Sciences 2002200 57-62. (https://doi. org/10.1016/s0022-510x(02)00133-8)

Received in final form 1 May 2021

Accepted 25 May 2021 